\title{
Exploring Relationship Between the Stock Price of Taiwan and the Exchange Rate: An Autoregressive Distributed Lag Model with a Quantile Regression
}

\author{
Tzu-Kuang $\mathrm{Hsu}^{1}$ \\ ${ }^{1}$ Department of International Business, Chung Hua University, Taiwan, Republic of China \\ Correspondence: Tzu-Kuang Hsu, Department of International Business, Chung Hua University, Hsinchu, \\ Taiwan, R.O.C. Tel: 886-3-518-6557. E-mail: hsutk@chu.edu.tw
}

Received: October 8, 2015

Accepted: October 30, 2015

Online Published: December 25, 2015

doi:10.5539/ijef.v8n1p72

URL: http://dx.doi.org/10.5539/ijef.v8n1p72

\begin{abstract}
This paper adopts an innovative method through combining an autoregressive distributed lag model and a quantile regression to examine the long-run equilibrium and short-run causal relationship between the stock price of Taiwan and the NTD/USD exchange rate from January 1980 to December 2014. The results indicate that there is long-run level equilibrium relationship between the stock price of Taiwan and the NTD/USD exchange rates at lower distribution of stock prices, and at higher and lower distribution of exchange rates. The causality results show that there is unidirectional causality running from Taiwan stock price to the NTD/USD exchange rate at higher distribution of exchange rates. The result shows that there is evidence in favor of the portfolio hypothesis.
\end{abstract}

Keywords: a quantile regression, autoregressive distributed lag model, exchange rates, portfolio hypothesis, stock prices

\section{Introduction}

Over two decades, the relationship between exchange rates and stock prices has been issues of concern to financials, governments, market participants, and the general public. The traditional approach asserted that the depreciation of domestic currency might affect firm's values through changes in competitiveness, thereby affecting firm's profits and their stock prices. On the other hand, the portfolio approach claimed that an increase in stock prices might induce a rise in domestic investor's wealth, leading to an increase in the inflows of foreign capital and thereby causing an appreciation in domestic currency.

In the international finance and international investment empirical literature, there exist four views regarding the causal relationship between exchange rates and stock prices. The first view argues that exchange rates cause stock prices (traditional hypothesis). The recent studies such as Bahmani-Oskooee and Sohrabian (1992), Abdalla and Murinde (1997), Granger, Huang, and Yang (2000), Nieh and Lee (2001), Fang (2002), Hatemi-J and Roca (2005), Tian and Ma (2010), among others support this hypothesis. The second view argues that stock prices cause exchange rates (portfolio hypothesis). This view has been supported by Bahmani-Oskooee and Sohrabian (1992), Smith (1992), Abdalla and Murinde (1997), Ajayi, Friedman, and Mehdian (1998), Granger, Huang, and Yang (2000), Phylaktis and Ravazzolo (2005), Tsai (2012), among others. The third view implies that both exchange rates and stock prices cause each other (feedback hypothesis). This view has been supported by studies such as Bahmani-Oskooee and Sohrabian (1992), Mok (1993), Ibrahim (2000). The fourth view implies that there is no causality between exchange rates and stock prices (neutrality hypothesis). This hypothesis has been supported by Ajayi, Friedman, and Mehdian (1998), Granger, Huang, and Yang (2000).

According to the conclusion derived from these studies, the previous empirical literature that focuses on causal relationship between exchange rates and stock prices is not conclusive to provide policy recommendation that can be applied across countries. In other words, the causal relationship between exchange rates and stock prices is still debatable. Furthermore, these empirical studies use ordinary least square (OLS) regression to test Granger causality that estimates the impact of the independent variable on the mean of the conditional dependent variable distribution, which only considers its conditional mean, that is, it cannot describe the dynamic relationship between the independent variable and the dependent variable. The methodology in this study, however, is totally 
different from the past research studies. We use an innovative regression, which combines Pesaran, Shin, and Smith (2001) developed the bounds test procedure which based on the Auto-Regressive Distributed Lag (ARDL) model, and Koenker and Bassett (1978) proposed a quantile regression, to investigate the dynamic long-run equilibrium relationship between stock prices and exchange rates, the short-run causal impact of exchange rates on stock prices across different conditional exchange rate distribution, and the short-run causal impact of stock prices on exchange rates across different conditional stock price distribution. Pesaran, Shin, and Smith (2001) ARDL method is more efficient because it does not require a pre-test for co-integration among variables and more robust to conduct long-run equilibrium test. Moreover, the advantage of using a quantile regression is that a quantile regression will be more robust (Koenker, 2005) because it estimates the median and the full range of other conditions, rather than ordinary least squares regression to estimate mean. This paper is organized as follows. In section II, we present and discuss the methodology. Section III reports data collection and empirical results. Section IV provides conclusions.

\section{Methodology}

\subsection{Autoregressive Distributed Lag Model}

To investigate the relationship between the stock price of Taiwan and the NTD/USD exchange rate during the period of January 1980-December 2014, this study employs an innovative approach through combining Pesaran, Shin, and Smith (2001) developed the Auto-Regressive Distributed Lag (ARDL) model and Koenker and Bassett (1978) proposed a quantile regression. Several empirical studies (Pesaran, 1997; Pesaran \& Smith, 1998; Pesaran, et al., 2001) have indicated that the ARDL approach for co-integration is preferable to other conventional co-integration approaches such as Engle and Granger (1987), Johansen (1988), and Johansen and Juselius (1990) procedures. One of the reasons for using the ARDL is that it has advantage of avoiding the classification of variables into $\mathrm{I}(1)$ or $\mathrm{I}(0)$ and no need for unit root pre-testing. Another reason for using the ARDL approach is that it is more robust and performs better for small sample sizes than other co-integration techniques. The third reason for preferring the ARDL approach is that it allows that the variables may have different optimal lags and employs a single reduced form equation to estimate the long-run relationship. Taking each of the variables in turn as a dependent variable in this study, we estimate the following Unrestricted Error Correction model:

$$
\begin{aligned}
& \Delta \operatorname{lnEXCH}_{t}=\alpha_{0}+\alpha_{1} \operatorname{lnEXCH}_{t-1}+\alpha_{2} \operatorname{lnTWSI}_{t-1}+\sum \alpha_{1 i} \Delta \ln E X C H_{t-i}+\sum \alpha_{2 i} \Delta \ln T W S I_{t-i}+\varepsilon_{l t} \\
& \Delta \operatorname{lnTWSI}_{t}=\beta_{0}+\beta_{1} \ln E X C H_{t-1}+\beta_{2} \ln T W S I_{t-1}+\sum \beta_{1 i} \Delta \ln E X C H_{t-i}+\sum \beta_{2 i} \Delta \ln T W S I_{t-i}+\varepsilon_{2 t}
\end{aligned}
$$

Here, lnEXCHt is the log of exchange rates which measures the price of USD in terms of the New Taiwan dollar (NTD) and lnTWSIt is the natural log of the Taiwan Weighted Stock Index. $\Delta$ is the first difference operator. To investigate the long-run relationship between the stock price of Taiwan and the NTD/USD exchange rate, this study uses the F-test statistic to test the joint significance of the coefficients on one-period lagged levels of the variables in Equation (1), denoted by $\mathrm{F}\left(\mathrm{EXCH}_{\mathrm{t}} \mid \mathrm{TWSI} \mathrm{I}_{\mathrm{t}}\right)$, that is, the null hypothesis $\mathrm{H}_{0}: \alpha_{1}=\alpha_{2}=0$ against the alternative $H_{1}: \alpha_{1} \neq \alpha_{2} \neq 0$. Similarly, the null hypothesis for testing the non-existence of a long-run relationship in Equation (2) is denoted as F(TWSI $\left.\left.\right|_{t} \mid E_{C X H}\right)$. Pesaran (1997) and Pesaran, Shin, and Smith (2001) provide critical values are based on large sample sizes. The bounds test procedure is applicable regardless of whether or not the underlying regressors are integrated on the order of one or zero, or are mutually co-integrated. The ARDL regression, on the other hand, yields a test statistic that can be compared to two asymptotic critical values. When the test statistic lies above the upper bound of critical values, the null hypothesis of a no long-run relationship is rejected whether or not the underlying orders of integration of the regressors are zero or one. Alternatively, when the test statistic is below the lower bound of critical values, the null hypothesis of a no long-run relationship among the regressors cannot be rejected. If the test statistic lies between these two bounds, the results are inconclusive.

In Equation (1), causality implies that lnTWSI 'Granger-causes' $\operatorname{lnEXCH}$ provided that $\alpha_{2 \mathrm{i}} \neq 0$ for all i. Similarly, in Equation (2), causality implies that $\operatorname{lnEXCH}$ 'Granger-causes' lnTWSI provided $\beta_{1 \mathrm{i}} \neq 0$ for all $\mathrm{i}$.

\subsection{A Quantile Regression}

A quantile regression is a statistical technique intended to estimate and conduct inference about conditional quantile function. Koenker and Bassett (1978) proposed the quantile regression approach as an alternative to least squares regression in a wide range of applications. This approach takes into consideration the skewness of the distribution and gives a more complete picture of the performance that is affected by the various independent variables. This technique was further developed by Koenker and Hallock (2001) and Koenker (2005).

According to Koenker (2005), a quantile regression is used when an estimate of the various quantile of a population is desired. One advantage of using a quantile regression to estimate the median and the full range of 
other conditions, rather than ordinary least squares regression to estimate mean, is that a quantile regression will be more robust in response to large outliers. Like the least absolute deviations, the quantile regression objective function is a weighted sum of absolute deviations, which gives a robust measure of location, so that the estimated coefficient vector is not sensitive to outlier observations on the dependent variable. In addition, it also provides a more efficient approach than the least square method when the error term is non-normal.

A quantile regression can be seen as a natural analogue in regression analysis to the practice of using different measures of central tendency and statistical dispersion to obtain a more comprehensive and robust analysis. Another advantage of a quantile regression is the fact that any quantile can be estimated.

According to Koenker and Bassett (1978) method, we let $\left\{y_{t}, t=1,2 \ldots, T\right\}$ be a random sample on the regression process $y_{t}=u_{t}+x_{t} \beta$, having conditional distribution function $F_{Y / X}(y)=F\left(Y_{t} \leq y\right)=F\left(y_{t}-x_{t} \beta\right)$, where $\left\{x_{t}, t=1,2 \ldots, T\right\}$ denote a sequence of (row) k-vectors of a known design matrix. The $\theta^{\text {th }}$ regression quantile, $Q_{Y / X}(\theta), 0<\theta<1$ is defined as any solution to the minimization problem

$$
\begin{gathered}
\min _{\beta}\left[\theta \sum\left|y_{t}-x_{t} \beta\right|+(1-\theta) \sum\left|y_{t}-x_{t} \beta\right|\right] \\
\left\{t: Y_{t} \geq X_{t} \beta\right\} \quad\left\{t: Y_{t}<X_{t} \beta\right\}
\end{gathered}
$$

The resulting solution to equation 3 is denoted as $\beta_{\theta}$, from which we obtain the $\theta^{\text {th }}$ conditional quantile $Q_{\gamma / x}(\theta)=$ $x \beta_{\theta}$. In this paper $y_{t}$ or $x_{t}$ can be the stock prices and the exchange rate.

\subsection{An ARDL Model with a Quantile Equation}

An innovative method through combining an autoregressive distributed lag model and a quantile regression, which substitutes equation 3 into equations 1 and 2, can be described to equations 4 and 5. It provides a useful supplement to the standard constant-parameter regression estimate (only one $\alpha$ or $\beta$ ) for studying all possible parameters (for all quantiles) vary across high dependent variable and low dependent variable. This method also leads to a more dynamic and complete understanding of what might really lie behind the stories of great effect or non-effect for the exchange rate on the stock price or the stock price on the exchange rate.

$$
\begin{aligned}
& \min _{\alpha} \theta \sum\left|\Delta \operatorname{lnEXCH}_{\mathrm{t}}-\alpha_{0}-\alpha_{1} \operatorname{lnEXCH}_{\mathrm{t}-1}-\alpha_{2} \operatorname{lnTWSI}_{\mathrm{t}-1}-\sum \alpha_{1 \mathrm{i}} \operatorname{LnEXCH}_{\mathrm{t}-\mathrm{i}}-\sum \alpha_{2 \mathrm{i}} \Delta \operatorname{lnTWSI}_{\mathrm{t}-\mathrm{i}}\right| \\
& +(1-\theta) \Sigma\left|\Delta \operatorname{lnEXCH}_{\mathrm{t}}-\alpha_{0}-\alpha_{1} \operatorname{lnEXCH}_{\mathrm{t}-1}-\alpha_{2} \operatorname{lnTWSI}_{\mathrm{t}-1}-\sum \alpha_{1 \mathrm{i}} \Delta \operatorname{lnEXCH}_{\mathrm{t}-\mathrm{i}}-\sum \alpha_{2 \mathrm{i}} \Delta \operatorname{lnTWSI} \mathrm{t}_{\mathrm{t}-\mathrm{i}}\right| \\
& \min _{\beta} \theta \sum\left|\Delta \operatorname{lnTWSI}_{\mathrm{t}}-\beta_{0}-\beta_{1} \operatorname{lnEXCH}_{\mathrm{t}-1}-\beta_{2} \operatorname{lnTWSI}_{\mathrm{t}-1}-\sum \beta_{1 \mathrm{i}} \Delta \operatorname{lnEXCH}_{\mathrm{t}-\mathrm{i}}-\sum \beta_{2 \mathrm{i}} \Delta \ln \mathrm{TWSI} \mathrm{t}_{\mathrm{t}-\mathrm{i}}\right| \\
& +(1-\theta) \sum\left|\Delta \operatorname{lnTWSI}_{\mathrm{t}}-\beta_{0}-\beta_{1} \operatorname{lnEXCH}_{\mathrm{t}-1}-\beta_{2} \operatorname{lnTWSI}_{\mathrm{t}-1}-\sum \beta_{1 \mathrm{i}} \Delta \operatorname{lnEXCH}_{\mathrm{t}-\mathrm{i}}-\sum \beta_{2 \mathrm{i}} \Delta \operatorname{lnTWSI} \mathrm{t}_{\mathrm{t}-\mathrm{i}}\right|
\end{aligned}
$$

If we investigate the short-run causality between exchange rates and stock prices, In Equation (4), causality implies that $\operatorname{lnTWSI}$ 'Granger-causes' $\operatorname{lnEXCH}$ provided that $\alpha_{2 \mathrm{i}} \neq 0$ for all i during different $\theta^{\text {th }}$ conditional quantile $Q_{Y / X}(\theta)=x \alpha_{\theta}$. Similarly, in Equation (5), causality implies that lnEXCH 'Granger-causes' InTWSI provided that $\beta_{1 i} \neq 0$ for all i during different $\theta^{\text {th }}$ conditional quantile $Q_{Y / X}(\theta)=x \beta_{\theta}$.

\section{Data and Empirical Results}

This study uses monthly Taiwan data that covers the period January 1980-December 2014 for a total of 420 observations. The data on NTD/USD exchange rate and Taiwan stock prices are compiled from the Taiwan Economic Journal. The NTD/USD exchange rate is measured as the price of US dollar in terms of New Taiwan dollar. Taiwan Stock prices are measured as the Taiwan Weighted Stock Index. All variables are in logarithmic form. 
First, this study uses the Augmented Dickey-Fuller (ADF) unit root test to determine the order of integration of the two variables. Table 1 reported the unit root test results in levels and first differences. The results show that we cannot reject the null hypothesis of the unit root for two variables in levels. When applying the ADF test to the first difference of these two series, we are able to reject the null hypothesis of a unit root at the $1 \%$ level or better. Based on the results from the ADF test, it is concluded that these two data series are integrated of order one.

Table 1. Results from the Augmented Dickey-Fuller unit root test

\begin{tabular}{lcccc}
\hline Variable & Level & p-value & First-difference & p-value \\
lnEXCH & -1.498 & 0.534 & -17.368 & 0.000 \\
$\ln$ TWSI & 1.956 & 0.306 & -18.909 & 0.000 \\
\hline
\end{tabular}

Note. $*$ Denotes significance at the $1 \%$ level.

In applying the bounds test, this paper first specifies the optimal lag length of the UECM on equations (1) to (2) and checks if there exists the long-run equilibrium relationship. This study employs the Schwarz's Bayesian Information Criterion (SBC) to choose the optimal lag length because the SBC tends to define more parsimonious specifications (Pesaran \& Shin, 1999). The lag order determined from the SBC is 1 . The $\chi_{\text {sc }}^{2}$ statistic also indicates that there is no serial correlation in the residual when the lag length is equal to 1.

Furthermore, the bounds tests without trend are conducted to confirm the existence of a dynamic long-run equilibrium relationship between the stock price of Taiwan and the NTD/USD exchange rate, and the results showed in Tables 2 and 3. Due to 420 observations, the critical values from Pesaran (1997) and Pesaran, Shin, and Smith (2001) will be used in the present study. Clearly, the computed F-statistics 1.009 and 1.945 are below the lower critical value 2.45 for $\mathrm{F}\left(\mathrm{EXCH}_{\mathrm{t}} \mid \mathrm{TWSI}_{\mathrm{t}}\right)$ and $\mathrm{F}(\mathrm{TWSIt} \mid \mathrm{EXCHt})$ by using traditional OLS method. However, using an innovative method, that is, ARDL with a quantile regression, the results found that there exist long-run relationship between the exchange rate and Taiwan stock price at the lower( 0.1 and 0.2 quantiles $)$ and higher(0.7 to 0.9 quantiles) distribution of the exchange rate for $\mathrm{F}\left(\mathrm{EXCH}_{\mathrm{t}} \mid \mathrm{TWSI}_{\mathrm{t}}\right)$ in Table 2, and long-run relationship between Taiwan stock price and the exchange rate at the lower distribution of Taiwan stock price for F(TWSIt|EXCHt) in Table 3.

Table 2. Co-integration test results at different quantiles for F(EXCHt|TWSIt)

\begin{tabular}{cl}
\hline Quantile & F value \\
\hline 0.1 & $4.351^{*}$ \\
0.2 & $7.568^{*}$ \\
0.3 & 2.971 \\
0.4 & 0.972 \\
0.5 & 0.560 \\
0.6 & 2.198 \\
0.7 & $5.564^{*}$ \\
0.8 & $4.988^{*}$ \\
0.9 & $6.750^{*}$ \\
OLS & 1.099 \\
\hline
\end{tabular}

Note. * Denotes significance at the $5 \%$ level.

Table 3. Co-integration test results at different quantiles for F(TWSIt|EXCHt)

\begin{tabular}{cc}
\hline Quantile & F value \\
\hline 0.1 & $11.185^{*}$ \\
0.2 & $5.205^{*}$ \\
0.3 & 1.228 \\
0.4 & 0.326 \\
0.5 & 0.073 \\
0.6 & 0.120 \\
0.7 & 0.209 \\
0.8 & 0.941 \\
0.9 & 3.216 \\
OLS & 1.945 \\
\hline
\end{tabular}

Note.* Denotes significance at the $5 \%$ level. 
The Granger causality test results are presented in Tables 4 and 5. The notation of $x \neq>y$ means that variable $x$ does not Granger-cause variable $y$. With respect to the causal relationship between the stock price of Taiwan and the NTD/USD exchange rate during the period of January 1980-December 2014, the findings are noteworthy. First, the relationship between the exchange rate and Taiwan stock price is neutral by using traditional OLS method. Second, through using an innovative method, there is unidirectional causality running from Taiwan stock prices to NTD/USD exchange rates, which supported the portfolio hypothesis, at the high distribution of exchange rates.

Table 4. Results from causality tests at different quantiles for $\operatorname{lnTWSI} \not>\operatorname{lnEXCH}$

\begin{tabular}{lll}
\hline Quantile & F value & p-value \\
\hline 0.1 & 1.008 & 0.316 \\
0.2 & 0.458 & 0.499 \\
0.3 & 0.005 & 0.941 \\
0.4 & 0.000 & 0.990 \\
0.5 & 0.005 & 0.946 \\
0.6 & 1.364 & 0.244 \\
0.7 & 2.015 & 0.157 \\
0.8 & 1.311 & 0.253 \\
0.9 & $4.633^{*}$ & 0.032 \\
OLS & 2.508 & 0.114 \\
\hline
\end{tabular}

Note. *Denotes significance at the $5 \%$ level.

Table 5. Results from causality tests at different quantiles for $\operatorname{lnEXCH} \neq>\operatorname{lnTWSI}$

\begin{tabular}{lll}
\hline Quantile & F value & p-value \\
\hline 0.1 & 0.016 & 0.899 \\
0.2 & 0.062 & 0.803 \\
0.3 & 0.419 & 0.518 \\
0.4 & 0.594 & 0.411 \\
0.5 & 0.013 & 0.908 \\
0.6 & 0.277 & 0.599 \\
0.7 & 0.228 & 0.634 \\
0.8 & 0.578 & 0.448 \\
0.9 & 0.683 & 0.409 \\
OLS & 2.015 & 0.157 \\
\hline
\end{tabular}

Note. *Denotes significance at the $5 \%$ level.

\section{Conclusions}

A number of empirical studies have examined the relationship between exchange rates and stock prices. This paper adopts an innovative approach through combining an autoregressive distributed lag (ARDL) model and a quantile regression to examine the long-run and short-run causal relationship between the stock price of Taiwan and the NTD/USD exchange rate during the period of January 1980-December 2014. According the traditional OLS method, the results clearly indicate that there is no long-run equilibrium and short-run causal relationship between the stock price of Taiwan and the NTD/USD exchange rate. However, through using an ARDL model with a quantile regression, the results show that there is a long-run equilibrium relationship between the exchange rate and Taiwan stock price. Moreover, there is unidirectional causality running from Taiwan stock price to the NTD/USD exchange rate at the high distribution of exchange rates, which supported the portfolio hypothesis. These empirical results also provide Taiwan's policymakers a better understanding of exchange rates and stock prices nexus, to formulate international financial policy in Taiwan.

\section{References}

Abdalla, I. S. A., \& Murinde, V. (1997). Exchange Rates and Stock Prices Interactions in Emerging Financial Markets: Evidence on India, Korea, Pakistan and the Philippines. Applied Financial Economics, 7(1), 25-35. http://dx.doi.org/10.1080/096031097333826 
Ajayi, R. A., Friedman, J., \& Mehdian, S. M. (1998). On the Relationship between Stock Returns and Exchange Rates: Tests of Granger Causality. Global Finance Journal, 9(2), 241-251. http://dx.doi.org/10.1016/S1044-0283(98)90006-0

Bahmani-Oskooee, M., \& Sohrabian, A. (1992). Stock prices and the effective exchange rate of the dollar. Applied Economics, 24, 459-464. http://dx.doi.org/10.1080/00036849200000020

Engle, R. F., \& Granger, C. W. J. (1987). Cointegration and Error Correction: Representation, Estimation and Testing. Econometrica, 55(2), 251-276.

Fang, W. (2002). The effects of currency depreciation on stock returns: Evidence from five East Asian economies. Applied Economics Letters, 9, 195-199. http://dx.doi.org/10.1080/13504850110054931

Granger, C. W. J., Huang, B. N., \& Yang, C. W. (2000). A Bivariate Causality Between Stock Prices and Exchanges Rates: Evidence From Recent Asian Flu. The Quarterly Review of Economics and Finance, 40(3), 337-354. http://dx.doi.org/10.1016/S1062-9769(00)00042-9

Hatemi, J. A., \& Roca, E. (2005). Exchange Rates and Stock Prices: Interaction During Good and Bad Times: Evidence From the ASEAN4 Countries. Applied Financial Economics, 15(8), 539-546. http://dx.doi.org/10.1080/09603100500056635

Johansen, S. (1988). Statistical Analysis of Cointegration Vectors. Journal of Economic Dynamics and Control, 12, 231-254. http://dx.doi.org/10.1016/0165-1889(88)90041-3

Johansen, S., \& Juselius, K. (1990). Maximum likelihood estimation and inference on co-integration with applications to the demand for money. Oxford Bulletin of Economics and Statistics, 52(2), 169-210.

Koenker, R., \& Bassett, G. (1978). Regression Quantile. Econometrica, 46, 33-49. http://dx.doi.org/10.2307/1913643

Koenker, R., \& Hallock, K. (2001). Quantile regression. The Journal of Economic Perspective, 15, 143-156. http://dx.doi.org/10.1257/jep.15.4.143

Koenker, R. (2005). Quantile Regression. Econometric Society Monograph Series. Cambridge University Press. http://dx.doi.org/10.1017/CBO9780511754098

Mok, H. (1993). Causality of interest rate, exchange rate and stock price at stock market open and close in Hong Kong. Asia Pacific Journal of Management, 10, 123-143. http://dx.doi.org/10.1007/BF01734274

Nieh, C., \& Lee, C. (2001). Dynamic relationship between stock prices and exchange rates for G7 countries. Quarterly Review of Economics and Finance, 41, 477-490.

Pesaran, M. H. (1997). The role of economic theory in modeling the long run. Economics Journal, 107, 178-191.

Pesaran, M. H., \& Smith, R. P. (1998). Structural analysis of cointegrating VARs. Journal of Economic Surveys, 12, 471-505. http://dx.doi.org/10.1111/1467-6419.00065

Pesaran, M. H., \& Shin, Y. (1999). An autoregressive distributed lag modelling approach to cointegration analysis. In S. Storm (Ed.), Econometrics and economic theory in the 20th Century: The Ragnar Frisch Centennial Symposium. Cambridge University Press, Cambridge, chapter 1. http://dx.doi.org/10.1017/CCOL0521633230.011

Pesaran, M. H., Shin, Y., \& Smith, R. J. (2001). Bounds testing approaches to the analysis of level relationships. Journal of Applied Econometrics, 16, 289-326. http://dx.doi.org/10.1002/jae.616

Phylaktis, K., \& Ravazzolo, F. (2005). Stock prices and exchange rate dynamics. Journal of International Money and Finance, 24, 1031-1053. http://dx.doi.org/10.1016/j.jimonfin.2005.08.001

Smith, C. E. (1992). Stock markets and the exchange rate: A multi-country approach. Journal of Macroeconomics, 14(4), 607-629. http://dx.doi.org/10.1016/0164-0704(92)90003-Q

Tian, G. G., \& Ma, S. (2010). The relationship between stock returns and the foreign exchange rate: The ARDL

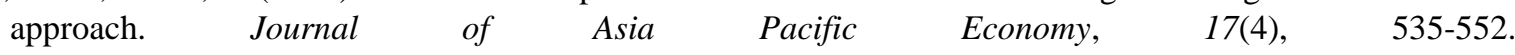
http://dx.doi.org/10.1080/13547860.2010.516171

Tsai, I. C. (2012). The relationship between stock price index and exchange rate in Asian markets: A quantile regression approach. Journal of International Financial Markets, institutions and Money, 22(3), 609-621. http://dx.doi.org/10.1016/j.intfin.2012.04.005 


\section{Copyrights}

Copyright for this article is retained by the author(s), with first publication rights granted to the journal.

This is an open-access article distributed under the terms and conditions of the Creative Commons Attribution license (http://creativecommons.org/licenses/by/3.0/). 